\title{
A migração de peruanos para a Amazônia Brasileira: uma discussão sobre redes migratórias, fronteiras e identidades
}

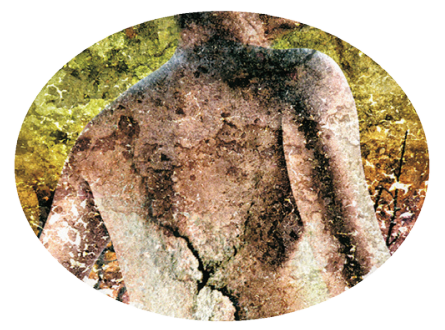

Alessandra Rufino Santos

\section{Resumo}

Este trabalho possui o objetivo de compreender a presença de peruanos no contexto amazônico brasileiro. Para isso, desenvolve um debate sobre o contexto social do local de origem e suas implicações na prática migratória. Dentre outros aspectos, esta análise proporciona a discussão sobre a forma como o Brasil torna-se uma opção de destino no processo migratório de peruanos, dando destaque a discussão acerca da mobilidade humana e suas implicações no espaço fronteiriço amazônico.

Palavras-chave: Migração de peruanos; Amazônia brasileira; redes migratórias; fronteiras e identidades

\section{Abstract}

This work has the objective of understanding the presence of peruvians in the amazon region of Brazil. It develops a debate about the social context of the place of origin and its implications in practice migration. Among other aspects, this analysis provides a discussion on how the Brazil becomes a destination of choice in the migration process of peruvians, highlighting the discussion of human mobility and its implications on the Amazon frontier space.

Keywords: Peruvian migration; Brazilian Amazon; migratory networks, borders and identities

\footnotetext{
* Estudante de mestrado do Programa de Pós-Graduação em Sociedade e Cultura na Amazônia (PPGSCA), da Universidade Federal do Amazonas (Ufam) e bolsista da Coordenação de Pessoal de Nível Superior (Capes).
} 


\section{Introdução}

Considerada um fenômeno da contemporaneidade, a migração tem sido discutida por diferentes campos da ciência. Entre as principais motivações para a sua prática, Siqueira (2008) destaca as questões econômicas a partir da existência de mercados de trabalho secundários nos locais de destino. Entretanto, Barth (2009: 19) expõe que o sentido migratório é muito mais que isso: "existem outros motivos, como os desejos de vivência em outro país, de mudanças e ampliação do conhecimento de outros processos culturais".

Essa nova concepção sobre a prática migratória ajuda a esclarecer que o processo social da migração precisa ser entendido como sendo organizado por meio de redes migratórias. Conforme Soares (2004), a noção desse conceito colabora com o entendimento de que, além de questões de ordem mais práticas como a viabilização de trabalho e hospedagem, as redes se configuram como local de memória e de reafirmação da identidade.

Hall (2003) defende que os locais das culturas são transitórios. Isso significa que quando um sujeito migrante cruza fronteiras culturais e geográficas distintas, este passa não apenas por uma mudança de localização, mas vivencia a construção de espaços simbólicos.

Essa nova tendência do fenômeno migratório contribui para a compreensão de que, neste trabalho, a dinâmica da migração é pensada a partir de sua notoriedade no limiar do século 21. Por isso, quando utilizamos o termo migração estamos nos referindo à prática de deslocamento tanto em nível nacional quanto internacional, com o intuito de salientar os fatores que estão para além do aspecto econômico, como as relações de sociabilidade, por exemplo. Nessa perspectiva, compreendemos a migração a partir do entendimento das redes migratórias, istoé, teias de relações sociais que valorizam as relações de parentesco, de amizade, de trabalho e de conterraneidade.

De acordo com o Relatório de Desenvolvimento Humano (PNUD, 2009), a maioria das pessoas que se desloca o faz dentro do seu país e soma algo em torno de 740 milhões de pessoas. Outro dado do PNUD (2009) é que entre as pessoas que se deslocaram atravessando fronteiras nacionais, a maioria são migrantes internacionais que se mudaram de um país em desenvolvimento para outro, ou entre países desenvolvidos. Isso corrobora com a afirmação de que o Brasil vem se tornando destino prioritário na América do Sul para os 
migrantes dos países fronteiriços.

Ainda segundo o mesmo relatório (PNUD, 2009), a partir da segunda metade do século 20 foi possível perceber o aumento expressivo de migrantes dirigindo-se para os países em desenvolvimento do continente americano. Países como o Brasil, a Argentina e a Venezuela passaram a receber um fluxo cada vez maior de migrantes dos países vizinhos. Contrariamente às migrações dos séculos 19 e 20, as migrações atuais na América do Sul registram dinâmicas migratórias que vinculam os países de origem com outros destinos migratórios dentro da própria América do Sul. Essa nova tendência das migrações internacionais, ou seja, migração entre os países que fazem fronteiras, abarcam desafios e potencialidades, sobretudo em vista da promoção dos direitos humanos e da integração regional.

Em torno dessa nova configuração, chama a atenção, no contexto urbano brasileiro, a presença crescente, a partir da década de 1950, de migrantes peruanos, que passaram a se inserir em alguns setores do mercado de trabalho brasileiro, tais como comércio, saúde, educação, gastronomia, entre outros. As razões que levaram esses migrantes a saírem de seu país de origem são múltiplas, porém é possível destacar a proximidade geográfica entre o Peru e o Brasil como um dos pontos mais impulsionadores dessa corrente migratória.

De acordo com Silva (2011), muitos dos peruanos que vivem em solo brasileiro são oriundos da Amazônia Peruana ou da capital, Lima. Para Oliveira (2007: 198), “durante muito tempo a cidade de São Paulo foi o destino mais procurado pelos migrantes peruanos que optaram pelo Brasil". Entre os motivos dessa escolha, a mesma autora destaca o fato de essa cidade ser uma grande metrópole, podendo apresentar uma grande diversidade cultural e maiores possibilidades de emprego.

No entanto, a partir da década de 1980, algumas cidades da Amazônia brasileira também passaram a ser ponto de referência para a migração de peruanos. Muitos passaram a escolher Manaus, capital do Estado do Amazonas e uma das principais cidades da Amazônia brasileira, para reconstruírem suas vidas. Outros seguiram sua trajetória rumo ao extremo Norte do Brasil, fixando moradia em Boa Vista, capital do Estado de Roraima, ou em Pacaraima, cidade que faz fronteira com a Venezuela. 


\section{O Peru no contexto das migrações e dos deslocamentos compulsórios}

O Peru é uma República Presidencialista Democrática, dividida em 25 (vinte e cinco) departamentos. ${ }^{1}$ A sua geografia é bastante variada, pois exibe tanto planícies quanto picos nevados e a floresta amazônica. Entre suas principais atividades econômicas estão a agricultura, a pesca, a exploração mineral e a manufatura de produtos têxteis. A língua espanhola é o idioma oficial, a população está estimada em 29,5 milhões, ${ }^{2}$ e é reconhecida por possuir um alto grau de mestiçagem. Do ponto de vista da economia, estudos da Comissão Econômica para a América Latina (CEPAL, 2011) consideram o Peru um país em desenvolvimento com um nível de pobreza em torno de 31,3\% da população.

Diante desse contexto, é importante ressaltar ainda que, desde os anos 1940 até os dias atuais, a sociedade peruana tem vivido uma intensa transformação populacional por conta dos movimentos migratórios internos, que têm sido causados por diferentes motivos relacionados, principalmente ao êxodo rural, que entre as suas principais causas podemos destacar: a deterioração da atividade rural, especialmente na região da serra; a escassez das terras agrícolas; o desequilíbrio econômico e a falta de oportunidades nas distintas regiões do país, sobretudo entre os anos de 1980 a 2000.

De uma população majoritariamente rural em 1940, o Peru passou a ter uma população urbana a partir de 1972. Essa tendência que seguiu em aumento para as grandes cidades peruanas, principalmente para a capital do país, o Departamento de Lima, que tem ocupado uma situação de privilégio, já que se converteu no principal centro das atividades político-administrativas do Peru, provocando um maior crescimento de sua população.

A Região Metropolitana de Lima tem expandido sua atividade industrial desde a década de 1950, ampliando o comércio e o setor de serviços. Em decorrência disso, experimentou um significativo crescimento de sua população que, sem dúvida, cresceu por conta das políticas migratórias.

Para Franco (1991), o processo de migração interna ocorrida no Peru é considerado o modo de expressão da ruptura histórica mais importante da sociedade peruana do século 20 , uma vez que representa a transição da sociedade rural para a sociedade urbana.

No que diz respeito ao processo de saída de peruanos para diversos 
países do mundo, Altamirano (2006) distingue cinco fases de acordo com os destinos escolhidos, a composição dos migrantes e as condições em que se deu esse fenômeno: a primeira fase vai de 1910 a 1949; a segunda que vai de 1950 a 1969; a terceira vai de 1970 a 1979; a quarta de 1980 a 1992 e a quinta fase, de 1993 até os dias atuais.

$\mathrm{Na}$ primeira fase, os migrantes podem ser divididos em dois grupos: o primeiro formado pela oligarquia comercial, que tinha como principal destino a Europa, principalmente Espanha e Inglaterra, já que, naquela época, viajar para a Europa significava ter grande prestígio e poder. Já o segundo grupo era representado por trabalhadores manuais, cujo principal destino era os Estados Unidos, para onde viajavam em busca de trabalhos como operários. Esse fluxo foi interrompido nos períodos da Primeira e Segunda Guerras Mundiais.

$\mathrm{Na}$ segunda fase, a classe média se juntou aos grupos mencionados acima. Profissionais liberais, empresários e estudantes dessa classe se dirigiram principalmente para os Estados Unidos, país que se encontrava em expansão econômica. Esse período coincide com a reconstrução europeia, após a Segunda Guerra Mundial. A saída de peruanos para a Europa Ocidental seguia sendo a preferência dos membros da oligarquia, ainda que no final desse período a França tenha recebido muitos estudantes. Contudo, ainda nessa época, peruanos deslocaram-se para países da América do Sul, como a Argentina e a Venezuela.

A terceira fase foi marcada pela ação de governos militares. Contudo, durante esses anos se ampliou o interesse em sair para a Europa. Foi a época em que os países socialistas começaram a receber peruanos. Além do mais, igualmente aos Estados Unidos, o Canadá e a Austrália passaram a receber muitos profissionais e trabalhadores especializados.

A quarta fase compreende o período da volta da democracia e, ao mesmo tempo, o início da maior violência política que o Peru já havia experimentado. Paralelamente iniciou uma crise econômica e, como consequência, o empobrecimento do pá́s. Um dos efeitos desse período foi o aumento da saída de peruanos para o exterior. Pela primeira vez, os países escandinavos receberam peruanos, em particular os refugiados políticos e trabalhadores econômicos, enquanto os países europeus recebiam estudantes. Por outro lado, países da América Central e do Sul começaram a receber com mais frequência trabalhadores peruanos qualificados e não qualificados. Os Estados Unidos e 
o Canadá também continuaram recebendo esses trabalhadores. O Japão, por sua vez, passou a abrir suas fronteiras para muitos trabalhadores econômicos. Contudo, foi possível visualizar peruanos se dirigindo a outras regiões como Caribe, o sul da Ásia e países árabes. Na verdade, é a partir dessa fase que as mulheres, sobretudo de zonas rurais e cidades pequenas da serra e da costa, se incorporaram entre as pessoas que decidiam sair do Peru para viver em outro país.

$\mathrm{Na}$ quinta e última fases, a migração para outros países tornou-se uma opção para todas as classes sociais e grupos culturais do Peru, exceto para os pobres do campo e das cidades e os nativos da Amazônia peruana que, como alternativa, passaram a se deslocar para os países vizinhos, em particular para o Brasil.

Para compreender a complexidade do ingresso dos migrantes peruanos no Brasil e na Amazônia brasileira, é necessário considerar que a migração peruana está pautada no tema dos deslocamentos compulsórios resultantes de um projeto político neoliberal que centraliza os bens e serviços numa relação marcada pelas desigualdades sociais. Além disso, também é importante considerar que a migração peruana está pautada no tema dos conflitos internos que se alastraram no período da ditadura militar no Peru.

Esse esclarecimento é necessário porque é importante levar em consideração que os migrantes econômicos do Peru, em situações adversas, foram forçados ao deslocamento compulsório, que, conforme Oliveira (2008), é a principal característica da mobilidade humana na tríplice fronteira Peru, Colômbia e Brasil. Diante desses apontamentos, é necessário ressaltar que a violência que força a saída de peruanos de seu país de origem pode ser justificada pelas imposições econômicas e o permanente conflito agrário da selva peruana que continuam sendo uma das principais causas da migração de trabalhadores econômicos.

De acordo com Oliveira (2008), esta análise torna-se pertinente pelo fato de situar os impactos da migração transfronteiriça ${ }^{4}$ na Amazônia brasileira, visto que até chegar ao destino desse itinerário, os sujeitos desse processo passam por vários estágios que vão desde os projetos migratórios, que implicam a opşão pela migração, até os fatores que implicam nos deslocamentos compulsórios, sumariamente forçados como é o caso dos refugiados. Segundo a mesma autora, o destaque para a expressão "opção pela migração" se deve 
à necessidade de se desenvolver estudos que problematizem os processos migratórios contemporâneos de forma crítica. Por isso que no capítulo seguinte esse trabalho dará destaque às abordagens teóricas que possuem como base as novas categorias da sociologia dos deslocamentos compulsórios.

Ainda de acordo com Oliveira (2008), duas correntes teóricas subsidiam as políticas migratórias na atualidade: o positivismo, que é responsável por sustentar a lógica da migração espontânea, tendo como base os projetos migratórios planejados e decididos sob a égide do livre-arbítrio; e a teoria crítica, que busca analisar os deslocamentos compulsórios a partir das contradições inerentes ao sistema capitalista que, na sua essência, produz os mecanismos que provocam a mobilidade humana, ora para deslocar mão de obra, ora para fazer circular as pessoas no mesmo nível da circulação das mercadorias, ora para servir aos interesses puramente econômicos abalizados pelos controles políticos transnacionais.

Para Milesi e Andrade (2010: 3),

é sempre oportuno repetir que nem todas as migrações são necessariamente resultado da exclusão e/ou da violência sofrida pelo ser humano. Algumas pessoas, que estão inseridas e plenamente situadas, podem livremente optar por sair de seu país/lugar de origem e colocar-se num processo migratório. Entretanto, essa não é a realidade da maioria. Assim, o pano de fundo do atual movimento migratório é a globalização em suas diversas expressões, positivas e negativas.

Bauman (2007) esclarece que a globalização, com predomínio econômico, põe em segundo plano muitos aspectos do processo de aproximação das pessoas e das nações. Em decorrência disso, questões referentes à mobilidade humana são tratadas, muitas vezes, como fluxo de mão de obra a ser aceita ou rejeitada em função de interesses meramente econômicos.

Essa redução do ser humano à simples mercadoria proporciona a reflexão de que os fluxos migratórios criam, muitas vezes, nos governantes e na população distintas representações que possibilitam, em grande parte dos casos, que os migrantes sejam vistos como ameaça no mercado de trabalho, no uso dos serviços públicos e no aumento da violência. 
Com essa visão distorcida, a questão migratória passa a ser vista pelo Estado brasileiro e pela própria população como problema. Diante desse contexto, a discussão sobre os deslocamentos compulsórios torna-se pertinente para compreender que em muitos casos das migrações atuais o ato de migrar é uma decisão forçada por motivos que variam desde as causas econômicas, as causas sociais, políticas e naturais.

Para esclarecer ainda mais essa discussão sobre deslocamentos compulsórios, cabe agora retomar algumas questões teórico-conceituais sugeridas por Vainer (2001: 182). Esse autor reconhece que os processos ligados à prática dos deslocamentos compulsórios denunciam a crise das "teorias migratórias" que, inspiradas no economicismo liberal neoclássico ou no economicismo do determinismo estruturalista, sistematicamente desconheceram a dimensão política do fato migratório. Dito em outras palavras, essas teorias são incapazes de compreender que as relações entre os grupos sociais, corpos e territórios remetem a processos de dominação e não apenas a processos econômicos.

Paradoxal ao momento em que se proclama um mundo sem fronteiras e a decomposição dos Estados, Vainer (2001: 183) expõe que "a crise vivenciada pelas teorias migratórias oferece uma chave de leitura para interpelar os novos espaços globais em construção e o discurso hegemônico que sobre eles se elabora e que pretendem legitimá-lo”. A crítica às limitações dessas teorias tradicionais não é suficiente, porém. Ao lado da tarefa teórica e conceitual, uma tarefa política desafia não apenas aos deslocados, clandestinos, exilados, refugiados e indocumentados, mas sim a todos os cidadãos do mundo.

\section{Brasil: Um lugar de destino para os migrantes peruanos}

Segundo divulgação do periódico El Comercio, em 2007, nas últimas décadas cerca um milhão e seiscentos e sessenta e cinco mil peruanos saíram de seu país, vindo aproximadamente 31.532 (trinta e um mil, quinhentos e trinta e dois) para o Brasil. Essa migração explicada, na maioria dos casos, pelas teorias migratórias tradicionais como estratégia predominantemente econômica para diferentes lugares do planeta e intensificou-se a partir das últimas décadas do século 20.

Muitos peruanos procuraram se instalar nos países vizinhos, fortalecendo 
o movimento migratório entre os países de fronteira. O Brasil é o destino mais procurado, havendo, na maioria das vezes, opção pela cidade de São Paulo, como já foi mencionado anteriormente.

Lucena (2006: 66) destaca que boa parte dos migrantes peruanos tinha a intenção de "utilizar a cidade de São Paulo como lugar de conexão para outros países europeus, porém acabaram se radicando na metrópole paulistana”. Ela afirma ainda que os grupos de peruanos instalados em São Paulo são heterogêneos, compreendendo uma faixa etária de vinte a quarenta anos de idade, com um número acentuado de solteiros e com um grau de escolaridade mais elevado, geralmente com nível médio.

Como já foi ressaltado, além de São Paulo, os peruanos se encontram também em outros Estados brasileiros, como é o caso do Rio Grande do Sul, Paraná, Rio de Janeiro, Minas Gerais, Amazonas, Acre, Roraima, e outras áreas de fronteiras. Nessas regiões predominam entre os migrantes as profissões liberais, técnicas e outras relacionadas ao comércio, ao setor de serviços, educação e saúde. No que diz respeito à composição étnica desses migrantes, Silva (2001: 491) destaca que "a maioria apresenta um componente étnico indígena relacionado às etnias aimará e quéchua. Muitos também utilizam a naturalização como forma de inserção na sociedade brasileira".

No cenário atual da globalização, as recentes tendências da migração de peruanos para o Brasil requerem uma incorporação de novas dimensões explicativas e uma reavaliação do contex to de luta e compromissos internacionais assumidos em prol da ampliação e efetivação dos direitos humanos desses migrantes. É bom lembrar também que Silva (2001: 489) reconhece que "o discurso da globalização, quando tomado de forma generalizada, incorre o risco de nivelar as diferenças e dificuldades enfrentadas por cada grupo de migrantes, nos mais diferenciados contextos sociais".

Os entraves jurídicos da documentação, por exemplo, são um elemento comum que nivela todos os migrantes peruanos, sejam eles qualificados profissionalmente ou não. Além de afetar os migrantes de forma direta, a indocumentação incide também sobre as famílias de cada um. Esse anacronismo transforma-se num dos empecilhos que os migrantes encontram para poderem desfrutar dos direitos e deveres que a cidadania implica.

Ainda sobre a questão dos direitos sociais, Silva (2001: 494) acredita que "as fronteiras geográficas e políticas precisam 'desaparecer' para dar 
lugar a uma maior circulação não só de bens e serviços especializados, mas também de oportunidades e bens culturais para toda a população". Isso nos estimula a perceber que os migrantes peruanos também são produtores de bens simbólicos e contribuem para tornar a dinâmica cultural brasileira mais plural e enriquecedora para todos.

Dessa forma, é importante afirmar que os migrantes peruanos procuram ser sujeitos da sua reprodução cultural, conquistando espaço na sociedade receptora. Simmel (1983: 183) compartilha dessa ideia ao afirmar que "a condição de estrangeiro significa que ele, que está distante, na verdade está próximo, pois ser um estrangeiro é naturalmente uma relação muito positiva: É uma forma específica de interação". Isso significa que, na medida em que os grupos formados pelas redes migratórias se tornam mais visíveis, os espaços sociais são fundamentais para desencadear o processo de negociação das identidades.

\section{A migração peruana no contexto amazônico}

A Amazônia, longe de ser homogênea, é uma região extremamente diversificada tanto em sua paisagem como em sua população. Localizada ao norte da América do Sul, atinge parte dos territórios dos Estados nacionais brasileiro, venezuelano, colombiano, peruano, boliviano, equatoriano, surinamês e guianenses (República Cooperativa da Guiana e Guiana Francesa). Segundo Aragón (2005), não existe consenso entre os pesquisadores para delimitar exatamente o tamanho dessa região e calcular sua população.

A Amazônia brasileira, por sua vez, abrange os Estados do Pará, Amazonas, Maranhão, Goiás, Mato Grosso, Acre, Amapá, Rondônia, Tocantins e Roraima perfazendo uma área que equivale a 61\% do território brasileiro. O IBGE divulgou, em 2009, que a população amazônica brasileira é estimada em 24,7 milhões de pessoas, das quais $62 \%$ habitam a zona urbana e 38\% a zona rural. Ou seja, a Amazônia brasileira deixou de ser, nas últimas décadas, uma região rural para tornar-se predominantemente urbana.

No entanto, o crescimento da população urbana na Amazônia brasileira não foi acompanhado por implementação de infraestrutura para garantir condições mínimas de qualidade de vida a seus habitantes. Esses problemas impactam fortemente as cidades amazônicas, entre elas a cidade de Manaus 
que, conforme Censo realizado pelo IBGE, em 2010, continua sendo a mais populosa capital da Amazônia brasileira, com 1.718 .584 (um milhão, setecentos e dezoito mil, quinhentos e oitenta e quatro) habitantes.

Nesse sentido, é possível inferir que o processo histórico de ocupação humana da região amazônica teve influência das migrações, principalmente as transfronteiriças, uma vez que a região faz fronteira com vários países, ao mesmo tempo em que se encontra em fase de estruturação e cujas dinâmicas são intensas e instáveis. Esse processo de ocupação da região amazônica brasileira tem sido objeto de detalhados estudos, sobretudo por parte de cientistas e pesquisadores sociais, já que os movimentos populacionais são fenômenos que influenciam não só a configuração e a ocupação da região amazônica, mas também os processos de multiculturalização.

A migração internacional para a Amazônia brasileira não é uma prática contemporânea. De acordo com Aragón (2009), a Amazônia brasileira acompanhou o período das grandes migrações do fim do século 19 e primeiras décadas do século 20. O fluxo de migrantes internacionais para o Brasil se fortaleceu a partir de 1870 e, sobretudo, após a abolição da escravatura, em 1888, como resultado de diversas transformações socioeconômicas e demográficas da Europa, da expansão do capitalismo e de políticas estatais do Brasil para atrair europeus para suprir a escassez de mão de obra causada pela liberação dos escravos. Os migrantes procediam, sobretudo, de Portugal, Itália, Espanha, Alemanha e Japão.

Emmi (2009) verifica que os Censos de 1872 a 1950 esclarecem que embora os estrangeiros tenham se concentrado na Região Centro-Sul do Brasil, espalharam-se por todo o país. Para a Amazônia, por exemplo, dirigiram-se principalmente portugueses, italianos, espanhóis, e sírio-libaneses, atraídos pela economia da borracha. Ainda na época da borracha havia, também, ingleses, franceses, norte-americanos e de muitas outras regiões e países. Os japoneses só passaram a se deslocar para Amazônia na década de 1930.

Ao contrário do que geralmente se pensa, mesmo após o colapso da borracha, muitos migrantes continuaram se deslocando para a Amazônia. Cabe lembrar que foram os estrangeiros, em especial os comerciantes, os pequenos industriais e trabalhadores em geral, os grandes responsáveis por sustentar a economia após o declínio da economia da extração do látex, já que chegaram a instalar pequenas fábricas e estabelecimentos comerciais para abastecer o 
mercado local, substituindo produtos que não podiam ser importados do mercado europeu (EMMI, 2009).

Após a Segunda Guerra Mundial, apesar dos esforços dos governos das distintas províncias existentes na Amazônia em estabelecer colônias agrícolas com mão de obra europeia, os projetos não prosperaram e a migração internacional passou a ocorrer de forma espontânea, concentrandose principalmente nas cidades. Recentemente, a análise das migrações internacionais para a região amazônica tem se concentrado no fluxo de entrada dos países vizinhos como Bolívia, Peru, Colômbia, Guiana, Venezuela, entre outros. Grande parte dos migrantes que se desloca para a Amazônia brasileira dirigiu-se para o Estado do Amazonas à procura de empregos gerados pela Zona Franca de Manaus e/ou por oportunidades de exploração florestal ou mineradora. É importante ressaltar que muitos deles permanecem na clandestinidade, isto é, sem documentação legal, à margem de qualquer levantamento estatístico.

A migração internacional na transfronteira amazônica, como em quase todos os processos de migração no mundo, é fruto de complexas redes sociais. Como afirma Oliveira (2008), a migração de países fronteiriços para o Brasil, em especial a Amazônia, não é um fenômeno novo, uma vez que depois de receber grandes fluxos migratórios provenientes da Europa, no início do século 20, o Brasil passou por uma fase de migração interna muito intensa, marcada predominantemente pelo êxodo rural. Foi somente a partir da década de 1970 que o Brasil passou a ser grande receptor de migrantes dos países fronteiriços vizinhos, como Bolívia, Chile, Paraguai, Peru e outros países latino-americanos.

A Amazônia brasileira, ao se inserir cada vez mais no circuito econômico internacional, reestrutura seus espaços e território numa malha de interesses cuja condição de fronteira mundial confere um sentido especial à mobilidade populacional. Os investimentos em tecnologia e em infraestrutura têm colaborado com o desenvolvimento e, consequentemente, atraído mais pessoas para a região. Tal questão implica entender que nesse início de século existe na Amazônia um novo patamar de expansão e integração nacional. $\mathrm{O}$ que antes era chamado de vazio demográfico, hoje simboliza uma realidade complexa constituída por múltiplos sujeitos portadores de diferentes matrizes de racionalidade, particularmente relevantes nesse momento em que mudanças 
de padrões tecnológicos e socioculturais se põem em questão (BECKER, 2004).

A Amazônia peruana é muito similar à Amazônia brasileira. Segundo Gow (2003), compreende 37\% do território peruano e sua população se concentra principalmente em suas duas principais cidades: Iquitos, no rio Amazonas, e Pucallpa, no Ucayali. Sua base produtiva está centrada na agricultura, na extração florestal e na extração de hidrocaburos.

O PIB da Amazônia peruana representa 6,7\% em relação ao PIB do Peru. O padrão de ocupação da Amazônia peruana é complexo, grande parte da população está concentrada em área de difícil acessibilidade e 50\% delas vivem nos centros urbanos. Habitam essa região mais de 300 mil indígenas distribuídos por 1.500 comunidades nativas reconhecidas e pertencentes a 65 grupos étnicos e 14 famílias linguísticas. Segundo Huallpa (2009), essa região tem um nível de pobreza altíssimo. Ou seja, 77\% da população vive na faixa da linha da pobreza e a desnutrição infantil atinge 35\% das crianças. Segundo esse mesmo autor, a partir de 1960, a Amazônia peruana recebeu grandes contingentes de migrantes provenientes da serra e costa peruanas. As causas para esse fenômeno seriam a reforma agrária, o surgimento da subversão, a hiperinflação, a crise econômica, o empobrecimento da região andina do Peru, o desemprego e o narcotráfico.

Podemos destacar também os aspectos políticos e econômicos do Peru, os conflitos agrários, o avanço do latifúndio e os processos de industrialização nos moldes capitalistas como elementos responsáveis por impulsionar a saída de homens e mulheres do Peru. Como já foi exposto, muitos peruanos migram num primeiro ciclo, dentro dos próprios limites regionais do Peru. Entretanto, esse processo se dá, primeiramente, dos pequenos povoados e aldeias interioranas para as cidades maiores, tais como Arequipa, Iquitos, Yurimaguas e Pulcallpa. De um modo geral, "a migração para a Amazônia peruana tem origem nas zonas alto-andinas; já a emigração da Amazônia peruana tem como destino a capital Lima e as cidades costeiras" (HUALLPA, 2009: 199).

Sobre a entrada de peruanos em território amazônico brasileiro, constatase que essa prática migratória passou a ter maior relevância a partir de meados da década de 1980, estendendo-se até os dias atuais. Trata-se, na verdade, de um fluxo eminentemente de migrantes trabalhadores que ingressaram na região sem os documentos necessários, permanecendo em situação irregular 
por muito tempo. Isso ocorre, inclusive, pela vastidão da selva amazônica que torna impossível um controle totalmente eficaz. O trânsito na fronteira é facilitado pela locomoção que é financeiramente mais viável, tanto via terrestre quanto via transporte fluvial (OLIVEIRA, 2008).

Os peruanos que migram para os Estados Unidos, Japão e/ou países da Europa são aqueles mais capitalizados ou que contam com uma boa rede de apoio, enquanto os que se deslocam entre os espaços transfronteiriços amazônicos seriam àqueles que dispõem de poucos recursos para uma migração, cujos investimentos iniciais seriam muito alto. A maioria dos peruanos que opta em migrar para o Brasil, em especial para a Amazônia brasileira, tem o seguinte perfil: em grande parte são homens, oriundos da região da selva peruana (Amazônia); apresentam um histórico de migração interna e um trânsito por distintas cidades da Região Norte do Brasil e alguns continuam a trajetória migratória com destino a países vizinhos, como é o caso da Venezuela. Outra característica do perfil de alguns peruanos é a baixa qualificação profissional. Quando chegam ao Brasil, muitos se tornam comerciantes informais e comercializam produtos diversos, como roupas e utensílios domésticos. Entretanto, apesar de algumas situações adversas enfrentadas pela maioria, o Brasil continua sendo um país das oportunidades e de múltiplas possibilidades de mobilidade econômica e social para parte dos migrantes peruanos (SILVA, 2009).

\section{A dinâmica da mobilidade humana transfronteiriça}

Como o universo empírico deste trabalho compreende uma discussão sobre fronteira e migração transfronteiriça, reconhecemos que a fronteira representa não só o desencontro de diferentes visões de mundo, como também a coexistência de diferentes espaço-temporalidades. Dessa forma, para Martins (1997: 150),

a fronteira é essencialmente o lugar da alteridade. É isso que faz dela um lugar singular: À primeira vista, é o lugar de encontro dos que, por diferentes razões, são diferentes entre si, como os índios de um lado e os civilizados do outro; como os grandes proprietários de terra, de um lado e os camponeses pobres, de outro. Mas o conflito faz com 
que a fronteira seja essencialmente, a um só tempo, um lugar de descoberta do outro e de desencontro.

Oliveira (2008: 3) também parte dessa abordagem e assume que “a fronteira é analisada enquanto uma 'situação' que pode estar indicando um processo de transitoriedade". Por isso, não se trata necessariamente de um "lugar", mas sim de um determinado contexto que possui variadas significações. Essa concepção ajuda a compreendermos a fronteira como a "passagem" de uma situação para outra adversa. Tal transição é dotada de conflitos que surgem ainda no processo migratório e fortalecem no encontro ou confronto com outros novos sujeitos sociais.

Castells (1999), por sua vez, esclarece que as fronteiras dão lugar as transformações simultâneas que podem ser influenciadas pelos sistemas de redes interligados. No caso da Amazônia, por exemplo, percebemos que, pelo grau de complexidade dessa região, o conceito de fronteira também se torna complexo.

No que diz respeito à percepção dos estudos migratórios, Oliveira (2008) afirma que a fronteira pode ser analisada como um lugar onde as diferenças se evidenciam e são gerados os conflitos culturais e sociais. Por outro lado, é na região de fronteira que as distâncias também se estreitam e as diferenças passam por um processo de elaboração de novos significados e possibilidades.

Em um ambiente de fronteira as migrações transfronteiriças são fortalecidas pelos processos de negociações das identidades, que, para Castells (1999: 22), representam "uma fonte de significado e experiência de um povo". Sendo assim, a identidade de um grupo não pode mais ser enfocada de forma abstrata e imutável, mas sim ser contextualizada a partir de um espaço e tempo de referência.

$\mathrm{Na}$ concepção de Robertson (1999), a globalização provoca um efeito descentralizador de identidades organizadas em torno de uma cultura e de fronteiras bem definidas, proporcionado o surgimento de novas posições de identificações mais plurais. Fica visível, portanto, que as identidades mudam de acordo com o espaço-temporal ou o modo como o sujeito é conhecido e reconhecido.

Nesse caso, à medida que os indivíduos migrantes venham a pertencer a dois mundos ao mesmo tempo, eles procuram preservar suas raízes, tradições 
e a memória que os ligam ao país de origem. No entanto, esses migrantes são motivados por novos diálogos que sustentam a necessidade de negociarem suas identidades em meio às novas culturas com as quais passam a ter contatos cotidianos.

Hall (1996: 95) defende que "as negociações das identidades das pessoas que atravessam as fronteiras nacionais estão relacionadas ao surgimento de novas culturas". Essa reflexão aponta para o fato de que, em tempos de globalização, não existe mais um único foco de identificação. As identidades podem ser ganhadas ou perdidas.

Segundo Haesbaert (1997), a identidade territorial, por exemplo, é um tipo de identidade que se expressa na relação de um grupo a partir da delimitação de uma escala territorial de referência identitária. Nesse sentido, os processos de negociação das identidades territoriais são efetivados a partir da interação entre os grupos sociais que se fortalecem por meio das redes migratórias.

Em relação ao percurso migratório de peruanos para o Brasil, o cruzamento de fronteiras de Estados brasileiros, que fazem divisa com o Peru, é uma prática essencial para que, posteriormente, esses migrantes possam fixar moradia em algumas cidades da Amazônia brasileira, mais especificamente na Região Norte do Brasil.

Santos (2010) verificou que parte dos peruanos que decidem migrar para o Brasil sai da capital Lima ou de alguma cidade média da região denominada de "Selva Peruana". Alguns pegam o voo até Iquitos e daí vão de barco até a pequena cidade peruana de Santa Rosa, que faz fronteira com o Estado do Amazonas. De Santa Rosa seguem até a cidade amazonense de Tabatinga, situada na fronteira do Peru com a Colômbia. Essa cidade, além de outras cidades do interior do Amazonas é, para muitos, apenas um lugar de passagem, pois o objetivo da maioria é chegar até a capital amazonense, a cidade de Manaus.

De acordo com Silva (2010), na cidade de Manaus, as atividades desenvolvidas pelos peruanos não diferem das atividades exercidas por outros migrantes nacionais e internacionais em cidades do interior, que na maioria dos casos são atividades informais. A diferença é que na capital amazonense as possibilidades de trabalho aumentam. Mas, de um modo geral, são poucos os peruanos com mão de obra qualificada e, por isso, dispõem-se a aceitar 
qualquer tipo de trabalho para garantir o sustento de suas famílias.

Santos (2010) destaca também que a trajetória migratória de alguns dos peruanos que estão vivendo no Norte do Brasil pode dar-se via Acre ou Venezuela. Os peruanos que chegam ao Acre saem de Lima até Cuzco, onde pegam o voo até Puerto Maldonado. Depois, seguem pela estrada do Pacífico, que cruza o Peru a partir da Amazônia peruana até o litoral, passando pela Cordilheira dos Andes até chegar a Iñapari, vilarejo peruano que faz fronteira com a cidade acriana de Assis Brasil. Após chegarem a Iñapari, muitos seguem em direção a Assis Brasil. Outros se deslocam para Brasileia, cidade acriana, que está pouco mais de $100 \mathrm{~km}$ de Assis Brasil e faz fronteira com a cidade boliviana de Codija. Após chegarem a Brasileia, alguns fixam moradia, já outros vão para a capital do Acre, Rio Branco, onde passam meses ou até anos e depois se mudam para Manaus. Após passar algum tempo em Manaus, migram para Boa Vista, já que é bastante comum receberem convites de familiares ou até mesmo de amigos. Depois de passarem algum tempo em Boa Vista, alguns chegam a migrar para outras cidades roraimenses, como Pacaraima, cidade que faz fronteira com a Venezuela. Outros vão mais adiante e adentram a Venezuela, mas após algum tempo retornam para Boa Vista.

Conforme se percebe na literatura acerca da migração, "as decisões pessoais dependem da atuação dos indivíduos na sociedade e de suas relações com outros indivíduos, o que proporciona a compreensão de que a migração é um processo seletivo e não aleatório" (ABUD et. al., 2008: 3). Nesse sentido, o entendimento das redes migratórias possui importância fundamental para a compreensão da mobilidade humana em regiões de fronteira.

Para Sasaki e Assis (2000), os migrantes não são indivíduos que agem desconectados de relações sociais. Diante dessa inferência, é possível perceber que as redes migratórias são capazes de fornecer apoio psicológico e material necessário aos migrantes.

Ainda segundo Sasaki e Assis (2000: 10),

as redes migratórias compõem um conjunto de laços sociais que ligam comunidades de origem e específicos pontos de destinos nas sociedades receptoras. Tais laços unem migrantes e não migrantes em uma complexa teia de papéis sociais complementares e relacionamentos interpessoais que são mantidos por um quadro informal de expectativas mútuas. 
De um modo geral, as redes migratórias são configuradas pelas redes de parentesco e sociabilidade. Assim, a escolha do destino migratório é determinada pela existência de um grupo de conterrâneos. Dessa forma, a escolha do local de destino pode ser baseada no grau de consolidação das redes. Estas, ao ficarem cada vez mais consolidadas, representam maior possibilidade de atenuar os riscos das migrações de longa distância, aumentando as chances do migrante a se adaptar no novo local de moradia (ASSIS, 2003).

É importante reconhecer que o projeto migratório - ou seja, a decisão de migrar, quem da família vai migrar, a "escolha" do local de destino, como e quando migrar - é orientado, em geral, pelas representações que são construídas no local de origem e pelas redes migratórias que direcionam e, ao mesmo tempo, realimentam os fluxos migratórios (SILVA, 2010).

Para Hall (2000), a migração das populações tem produzido grupos sociais - como é o caso da comunidade peruana que vive na Amazônia brasileira - constituídos cultural ou etnicamente, que tentam construir uma vida em comum e criar estratégias de convivência e formas de comunicabilidade, ao mesmo tempo em que são fortemente marcados por manterem costumes e práticas sociais específicas na vida cotidiana. A base de sustentação desse tipo de sociedade é o estabelecimento de um referencial no qual os conflitos mais graves de perspectivas, crenças ou interesses são negociados.

Nessa perspectiva, a identidade precisa ser analisada a partir do contexto das práticas sociais. O conceito de identidade que adotado neste trabalho é aquele que permite abordá-la não na qualidade de fenômeno apenas relacional, mas como fenômeno performático. Como refere Velho (1994), os indivíduos, mesmo nas passagens e trânsitos, entre domínios e experiências diferenciadas, mantêm, em geral, uma identidade vinculada a seu grupo social de origem. Contudo, os códigos culturais associados a distintos contextos permitem que os sujeitos migrantes estejam em permanente processo de negociação de suas identidades.

\section{Notas}

1 Amazonas, Ancash, Apurimac, Arequipa, Ayacucho, Cajamarca, Callao, Cusco, Huancavelica, Huánuco, Ica, Junin, La Libertad, Lambayeque, Lima, Loreto, Madre de Dios, Moquegua, Pasco, Piura, Puno, San Martin, Tacna, Tumbes e Ucayali.

${ }^{2}$ A projeção de população efetuada pelo Instituto Nacional de Estadistica e Informática (Inei) estima esse número de habitantes no Peru em 2012. 
${ }^{3}$ De acordo com Rodrigues (2006), a migração transfronteiriça pode ser entendida como a migração que ocorre em territórios contíguos a uma determinada fronteira nacional, ou seja, as migrações ou trânsito entre fronteiras de países vizinhos, zonas e regiões fronteiriças.

\section{Referências}

ABUD, Daniel Lamela et. al. Migração de retorno: entre significados e materialidades. In: Anais do XVI Encontro Nacional de Estudos Populacionais (Abep). Caxambu, 2008.

ARAGÓN, Luis E. (Org.). Populações da Amarônia. Belém: Naea / UFPA, 2005. - Aproximação ao estudo da migração internacional na PanAmazônia. In: ARAGÓN, Luis E. Migração Internacional na Pan-Amazônia. Belém: Naea / UFPA, 2009.

ASSIS, Gláucia de Oliveira. Criciúma para o mundo - os novos fluxos da população brasileira: gênero e rearranjos familiares. In: MARTES, A. C.; FLEISCHER, S. (Orgs.). Fronteiras cruzadas: etnicidade, gênero e redes sociais. São Paulo: Paz e Terra, 2003.

ALTAMIRANO, Teófilo. Remesas y nueva "fuga de cérebros" - impactos transnacionales. Lima: Fondo Editorial de la PUC, 2006.

BARTH, Daiani Ludmila. Brasileiros na Espanba: Internet, migração transnacional e redes sociais (Dissertação de Mestrado). São Leopoldo: Unisinos, 2009.

BAUMAN, Zygmunt. Tempos líquidos. Rio de Janeiro: Zahar, 2007.

BECKER, Bertha. Amazônia: Geopolítica na virada do III Milênio. Rio de Janeiro: Garamound, 2004.

CASTELLS, Manuel. A Sociedade em Rede. São Paulo: Paz e Terra, 1999.

CEPAL - Comissão Econômica para a América Latina e o Caribe. Panorama social da América Latina, 2011. Disponível em: <http://www.eclac. $\mathrm{cl} /$ publicaciones/xml/3/45173/2011-820-PSP-Sintese-Lanzamiento.pdf>. Acesso em: $1 . \% / 4 / 2012$.

EL COMERCIO. Um millón 665 mil peruanos se fueron del país entre los años 
1990 y 2005. Disponível em: <www.elcomercioperu.com.pe/edicionOnline/ Html/2007/>. Acesso em: 12/11/2011.

EMMI, Marília. Fluxos migratórios internacionais para a Amazônia Brasileira no final do século XIX ao início do século XX: O caso dos italianos. In: ARAGÓN, Luis E. Migração Internacional na Pan-Amazônia. Belém: Naea / UFPA, 2009.

FRANCO, Carlos. Exploraciones en “outra modernidad”: De la migración a la plebe urbana. In: Modernidad en los Andes. Cera. Cuzco: Bartolon de Las Casas, 1991.

GOW, Peter. "Ex-cocama": Identidades em transformação na Amazônia Peruana. In: Revista Mana, 2003.

HAESBAERT, R. Des-territorialização e Identidade: a rede "gaúcha" no Nordeste. Niterói: Eduff, 1997.

HALL, Stuart. Identidade cultural e diáspora. In: Revista do Patrimônio Histórico e Artístico Nacional, n. 24 , 1996, p. 68-75. - A identidade cultural na Pós-modernidade. Rio de Janeiro: DP\&A, 2000.

. Da Diáspora: identidades e mediações culturais. Belo Horizonte: Editora UFMG; Brasília: Representações da Unesco no Brasil, 2003.

HUALLPA, Luis Limachi. Procesos migratorios em la Amazonia Peruana: Uma mirada a las migraciones internacionales. In: ARAGÓN, Luis E. Migração Internacional na Pan- Amąônica. Belém: Naea / UFPA, 2009.

IBGE - Instituto Brasileiro de Geografia e Estatística. Censos Demográficos. Disponível em: <http: //www.ibge.gov.br>. Acesso em: 14/7/2011.

. Primeiros resultados do Censo Demográfico 2010. Disponível em: <http://www.ibge.gov.br>. Acesso em: 14/7/2011.

LUCENA, Cecília Toledo. Saberes e sabores do país de origem como forma de integração. In: Cadernos Ceru, vol. 19, n. ' 1. São Paulo: USP, 2008.

MARTINS, José de Souza. Fronteira: A degradação do outro nos confins do humano. São Paulo: Hucitec, 1997. 
MILESI, Rosita; ANDRADE, William Cezar de. Migrações internacionais no Brasil: Realidade e desafios contemporâneos. In: Instituto Migrações e Direitos Humanos, 2010. Disponível em: <http://www.gritodelosexcluidos.org/media/ uploads/migracionesintbr.pdf / >. Acesso em: 10/1/2012.

OLIVEIRA, Márcia Maria de. Mobilidade humana na tríplice fronteira PeruColômbia-Brasil e seus reflexos na cidade de Manaus (AM). In: SEYFERTH, Giralda; PÓVOA, Helion; ZANINI, Márcia Catarina; SANTOS, Mirian (Orgs.). Mundos em movimento: Ensaios sobre migrações. Santa Maria: Editora da UFSM, 2007.

. Migrações fronteiriças: Uma reflexão necessária no amazonas. Anais V Simpósio Internacional do Centro de Estudos do Caribe no Brasil. Salvador, 30 de setembro a 3 de outubro de 2008.

- Refugiados e desplaz̧ados na Amazônia: Contribuições para a Sociologia dos deslocamentos compulsórios. (Dissertação de Mestrado). Manaus: Ufam, 2008.

PNUD - Programa das Nações Unidas para o desenvolvimento. Relatório de Desenvolvimento Humano 2009. Disponível em: <www.pnud.org.br/rdh>. Acesso em: 4/5/2011.

RODRIGUES, Francilene dos Santos. Migração transfronteiriça na Venezuela. In: Estudos Avançados 20 (57). São Paulo: Edusp, 2006, p. 197-207.

ROBERTSON, R. Globalização. Petrópolis, RJ: Vozes, 1999.

SALES, T.; BAENINGER, R. Migrações internas e internacionais no Brasil. In: Travessia: Revista do Migrante. São Paulo: Paulinas, 1997.

SANTOS, Alessandra Rufino. Trajetórias migratórias e identidades reveladas: A presença de peruanos em Boa Vista/RR (Monografia). Boa Vista: UFRR, 2010.

SASAKI, Elisa Massa; ASSIS, Gláucia de O. Teoria das migrações internacionais. In: Anais do XII Encontro Nacional de Estudos Populacionais (Abep), Caxambu-MG, 2000.

SILVA, Sidney da. Hispano-americanos no Brasil entre a cidadania sonhada e a concedida. In: CASTRO, Mary Garcia (Org.). Migrações internacionais: 
Contribuições para a política. Brasília: CNPD, 2001.

- Hermanos Amazônicos: Peruanos e colombianos na Tríplice Fronteira e em Manaus. GT 14 - Migrações Internacionais: fronteiras e diversidades étnico-culturais. II Reunião Equatorial de Antropologia / XI Reunião de Antropólogos do Norte/Nordeste. Natal: UFRN, 19 a 22 de agosto de 2009.

. Hermanos Amazônicos: Processos identitários e estratégias de mobilidades entre peruanos e colombianos em Manaus. In: SILVA, Sidney A. da (Org.). Migrantes em contextos urbanos: uma abordagem interdisciplinar. Manaus: Edua, 2010.

- Peruanos em Manaus, Boa Vista e Pacaraima: Trajetórias e processos identitários. In: XI Congresso Luso-Afro-Brasileiro de Ciências Sociais. Salvador: UFBA, 7 a 10 de agosto de 2011.

SIMMEL, Georg. O estrangeiro. In: MORARES FILHO, Evaristo (Org.). Simmel. São Paulo: Ática, 1983.

SIQUEIRA, Sueli. Migracion y las distintas formas de retorno al suelo natal. Uma perspectiva transnacional. In: Simposio Internacional Nuevos retos del transnacionalismo en El estudio de las migraciones. Barcelona: Universitá Autonoma del Barcelona, 14 y 15 de febrero de 2008.

SOARES, Weber. Análise das redes sociais e os fundamentos teóricos da migração internacional. Campinas, Revista Brasileira Estudos Populacionais, v. 21, n. ${ }^{\circ}$ 1, p. 101-116, jan.-jun., de 2004.

VAINER, Carlos B. Deslocados, reassentados, clandestinos, exilados, refugiados, indocumentados: As novas categorias de uma sociologia dos deslocamentos compulsórios e das restrições migratórias. In: CASTRO, Mary Garcia (Org.). Migrações internacionais: Contribuições para a política. Brasília: CNPD, 2001.

VELHO, Gilberto. Projecto e Metamorfoses. Rio de Janeiro: Jorge Zahar Editora, 1994. 